\title{
Library as Showcase: Reflections on a Roundtable Discussion
}

\section{By Deborah Wills}

\begin{abstract}
Based on a roundtable discussion at ACRL 2015, this article explores the benefits and challenges of showcasing and celebrating the creative output of our communities. Such ventures serve the dual purpose of highlighting the contributions of our students, faculty, staff and alumni, while establishing the library as a centre for collaboration and cultural enrichment.
\end{abstract}

As academic librarians, we see our libraries at the centre of campus life, and they indeed function as a gathering place for research and study. However, our spaces can take a more active role in celebrating the creative output of our community members. By inviting musicians, artists, authors and other creators and performers into our buildings, we can provide opportunities for education, enrichment, conversation and inspiration. Participants benefit from increased exposure to their work and to interactions with like-minded peers, while the profiles of our libraries are raised on campus and beyond. Events and programs that focus on our creative community members can be powerful marketing tools, fostering goodwill and even attracting donors to our libraries. These endeavours also provide opportunities for collaboration with academic departments, student associations, alumni, the bookstore, the campus art gallery and other community partners. The result is a library more firmly embedded in the life of the campus.

At the conference of the Association of College \& Research Libraries in Portland this March, I led a roundtable discussion to explore the benefits and challenges of using library spaces to showcase and celebrate the creative output of our communities. Joining me were Chris Davidson from Northwestern University; Alex Regan from the University of California, Santa Barbara; Brittney Thomas from the University of lowa; and Amy Wainwright from John Carroll University. Each of our libraries has hosted a variety of events, including musical performances, exhibits, plays, poetry readings, author celebrations and class presentations. While we have found these events rewarding for both our users and our libraries, we acknowledged the challenges, and discussed how to balance the competing demands for library space, how to market to increase our audience, and how to ensure the relevance of these activities for our users and our libraries.

All involved in the roundtable agreed that such events have both expected and unexpected benefits. We all receive positive feedback from participants and notice the energy and excitement generated. Both Regan and Thomas mentioned hearing from audience members who have felt personally connected to items on exhibit and have come away with new thoughts and insights. At my library, at Wilfrid Laurier

Deborah Wills is Liaison Librarian for Music, Communication Studies, English, Film Studies and Journalism at Wilfrid Laurier University Library. 
University, student concerts have led to other performing opportunities for the participants. In addition, the library has benefited from the lively photos of events that we use in social media, our annual reports and other communications.

All participants also agreed that having a dedicated space for events in the library is the best approach. At her institution, Thomas has the benefit of working within a new learning commons, but most of us must carve space from that already used for other purposes without disadvantaging our regular users. While many of our users enjoy a music concert or author reading, others find these events distracting, or they may resent the loss of study space. Wainwright suggests using the public address system to alert users to upcoming events; they may then choose to join in or to move to another area. Davidson provides signage well in advance, including directions to quiet study spaces. At my own library, performance and exhibit space is near the entrance, to attract users entering or leaving the building. The main floor of our library is accepted as a "noisy" area, while our top floor is dubbed "Silent Seven."

Promotion is essential to the success of showcase events and can attract new visitors to our buildings along with potential donors. Wainwright recommends marketing in "every way possible." Examples include postering, electronic signage, and making strategic use of the web and social media. For those of us lucky enough to have dedicated communications staff at the library, or access to professional marketing staff on campus, expertise is at hand. However, as Davidson points out, library marketing on its own is of limited usefulness. His approach is to act as the "middle man" between students and the library, and he has good success when students take charge of their own promotion. He sees the library's role as providing the space and allowing students the responsibility for both the events and the marketing.

Regan believes that the library should provide not just space but also programs with particular meaning for the participants. For example, a photography exhibit at her library created personal resonance for the students who took part. She finds it rewarding but also time consuming and expensive to engage with different campus groups to make such programs successful.

Thomas has found that partnering with student groups is not always a reliable way to raise an audience for events in the library. However, she has had success connecting with faculty and staff on campus. She particularly recommends showcasing student work that is connected to a specific class, in part because this creates a built-in audience of classmates. In one case, students decided for themselves which of their class presentations should be exhibited at the library. Seeing their work showcased outside the classroom and in a frequently visited part of campus helped legitimize their efforts in their own eyes and in the eyes of their audience.

At my institution, library promotion has had limited success in building audience. For our Music in the Library series, even our inclusion in the Faculty of Music events calendar and on electronic signage at the university entrance has had minimal effect. Given the quantity and quality of music on campus and in the outside community, we recognize that we are competing for a limited audience and need to make our events relevant to our space and our users. For example, for the coming year, we plan to make our concerts more informal-to encourage people to move in and out of the space while the musicians 
perform. Marketing concerts as breaks from study and stress may appeal to our library users. To create the right atmosphere, we will try abandoning our rows of seating and replacing them with stand-up tables. We will also consult with our "alumni" - those students who have performed at the library in the past-and revisit our branding for the series. The use of the term "concert" may itself be problematic.

While the roundtable did not address the topic of funding, this can be a significant challenge. Some events, such as student concerts, may require only a small outlay for refreshments, signage and programs. However, more ambitious undertakings, such as a community author celebration, require considerable funds to make the events successful and memorable. Each library needs to decide on a reasonable budget for such endeavours and to recognize when partners and sponsors will be needed.

All of these issues point to the value of formulating policies and procedures and establishing an evaluation process. We may elect to sponsor an occasional event or embark on full-blown programs. For any endeavour, we need to balance the investment of time, money and effort against potential benefits. Details will vary from event to event; for example, mounting an art exhibit will require a process for selecting artists and installing their work. Establishing a program to celebrate authors will require a committee of stakeholders and an appropriate division of labour. In each case, the first task should be to establish goals, while considering the audience and purpose.

That said, when we are showcasing campus creativity, we should also use this opportunity to develop our own creative approaches. We should be ready to try new things, to learn from successes and failures, to cut losses, and to be open to unexpected benefits. The potential for enhancing the image of the library, along with spotlighting our many talented community members, makes such endeavours worthwhile. All libraries should feel encouraged to open their doors to campus creativity.

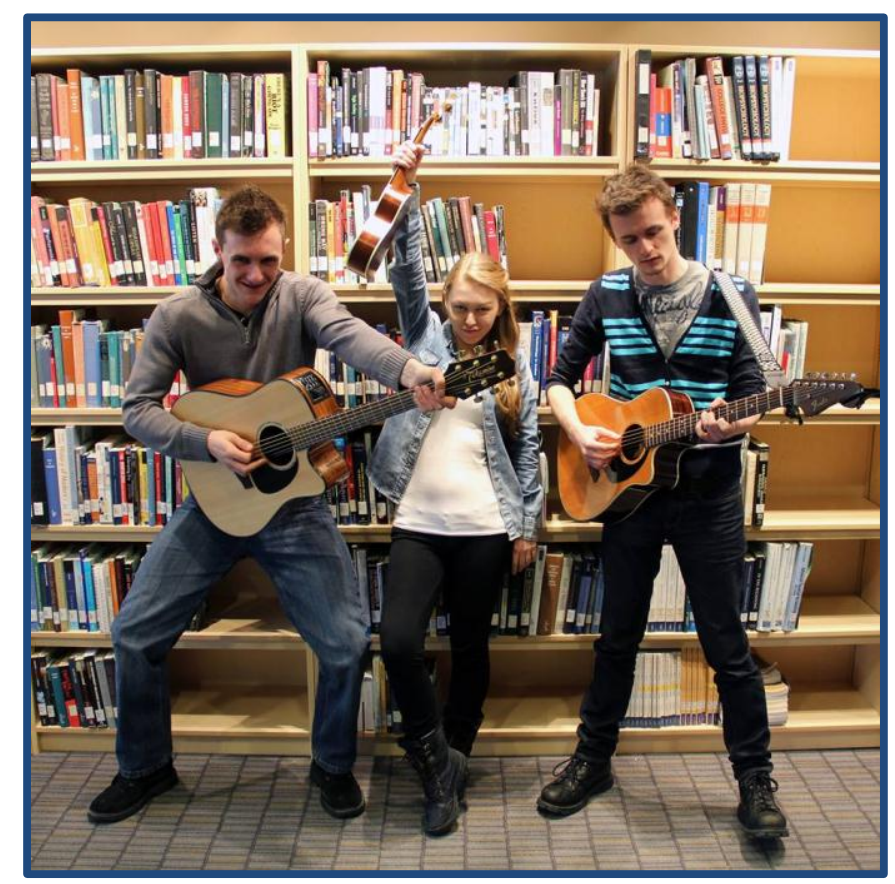

"Music in the Library" concert series, Laurier Library 